\title{
A alegria do Evangelho e sua incidência em nossa Igreja*
}

Mario de França Miranda

Salta aos olhos a vastidão do tema que me propôs a CNBB. Pois, seja a riqueza da temática presente na Exortação Apostólica do papa Francisco, sejam as numerosas e variadas atividades pastorais desenvolvidas por nossa Igreja, exigiriam um estudo mais completo e um tempo mais longo de exposição. Por isso mesmo, tivemos que optar por um determinado enfoque que possibilitasse nossa exposição. Uma opção subjetiva, portanto incompleta e sujeita a correções. Não nos deteremos naquilo que já constitui uma realidade positiva na Igreja em nosso país. Procuraremos, isto sim, examinar os estímulos que podemos receber da Exortação Apostólica Gaudium Evangelii em vista de uma maior sintonia com a Igreja Universal e de um melhor desempenho em nossa missão apostólica. Para isso examinaremos como os fundamentos desta Exortação Apostólica estão já presentes na eclesiologia do Concílio Vaticano II e também, especialmente, no Documento de Aparecida. Naturalmente compete à CNBB concretizar as orientações do papa Francisco para o nosso contexto. Portanto, neste ponto, apenas farei breves menções em forma de perguntas.

Começaremos com uma parte inicial, de cunho histórico, para que melhor possamos compreender de onde parte a iniciativa de renovação eclesial do atual pontífice. Não podemos entender o presente senão à luz do passado. $\mathrm{O}$ conhecimento das transformações de cunho institucional ocorridas no passado

* Este texto, sobre Conjuntura Eclesial, foi alocução apresentada na Assembleia Anual da CNBB no dia 30/04/14 em Aparecida/SP. 
nos torna mais receptivos às mudanças que os tempos atuais nos pedem. Numa segunda parte exporemos temáticas que nos parecem marcantes no texto do papa Francisco. Reconheço, de antemão, que certamente faltarão algumas questões, ou que algumas delas mereceriam um tratamento mais cuidado.

\section{O que nos ensina a História}

A história é fundamental para compreendermos a sociedade e a Igreja em que vivemos. Pois acertos e erros do passado repercutem ainda fortemente em nossos dias. A Igreja é uma realidade humano-divina. Enquanto divina existe por iniciativa do próprio Deus e goza de características que definem sua identidade teológica: a fé na pessoa de Jesus Cristo, a proclamação da Palavra de Deus, a missão pelo Reino de Deus, a celebração dos sacramentos, especialmente do batismo e da eucaristia, o ministério ordenado, a comunidade dos fiéis. Porém ela é também uma comunidade humana, encarnada na história, já que seus membros vivem em contextos socioculturais e existenciais concretos. Somente enquanto são filhos da sociedade onde vivem, dispõem de uma linguagem, de instituições sociais, de parâmetros de comportamento que possibilitam tanto a convivência humana, quanto professarem e viverem sua fé cristã como comunidade eclesial. Só configurando sua identidade teológica ao contexto onde se encontra pode a Igreja ser captada e entendida como Igreja, e, portanto, realizar sua missão de proclamar a salvação de Jesus Cristo para o mundo. Caso contrário ela será vista como realidade arcaica, peça de museu, não significativa nem pertinente para nossos contemporâneos.

E a história nos comprova que as sociedades, as mentalidades, as instituições sociais, as linguagens, os parâmetros de comportamento, se transformam e se sucedem no curso dos anos. E a Igreja deve poder ser captada, entendida, experimentada pela sociedade como sinal, sacramento da salvação de Jesus Cristo para o mundo. Caso contrário ela será considerada realidade do passado, que nada tem a dizer para a vida atual. Portanto, ela deve mudar sua configuração institucional para manter sua identidade de mediação salvífica, que é afinal o sentido de sua existência. Daí se explicam as mudanças históricas ocorridas no culto, nas expressões doutrinais, na organização comunitária, nas linhas pastorais, no serviço da caridade. Daí a afirmação de que a Igreja vive um processo histórico contínuo de institucionalizar a si própria. Se temos dificuldade em aceitar as mudanças que urgem é porque uma determinada configuração institucional histórica condiciona nossa compreensão da 
própria Igreja, incapacitando-nos imaginá-la diferente. Época de mudanças é igualmente época de resistências a mudanças.

As mudanças institucionais já aconteceram nos primeiros séculos devido aos diversos contextos das comunidades cristãs, mas a era constantiniana representa um marco decisivo na história da Igreja. Antes tolerado, disperso e perseguido, o cristianismo é elevado a religião oficial dotada de favores e benefícios, assumindo então do império a sua estrutura organizativa. O clero recebe importantes privilégios, os bispos são equiparados aos senadores e desempenham mesmo funções administrativas civis, o papa adquire posição imperial com as insígnias correspondentes, a liturgia adota um cerimonial com muitos elementos provenientes da corte. Sem negarmos as vantagens desta mudança para a propagação da fé e o fortalecimento institucional da Igreja, devemos observar entretanto que a comunidade dos fiéis passa a ser simplesmente a própria sociedade, entendendo-se por Igreja a Igreja dos clérigos. Desaparece a distinção Igreja e sociedade e emerge mais fortemente uma outra: a distinção de clero e laicato no interior da Igreja. Nesta época se valoriza muito a dimensão institucional plasmada pelo regime feudal estritamente hierarquizado: categorias de pessoas, status e prestígio social, fatores que em parte persistem até nossos dias.

A intromissão dos príncipes na nomeação dos bispos e os abusos do clero provocarão como reação a reforma gregoriana, alicerçada em princípios jurídicos para poder enfrentar o poder civil, que marcará profundamente a eclesiologia até hoje. Também a tendência ao centralismo papal se deve às mesmas razões, tornando a sede romana o eixo pelo qual Deus realiza seu desígnio salvífico, eixo este sustentado pelas estruturas jurídicas do feudalismo, que diminui bastante o papel dos bispos e das Igrejas Locais com relação a realidade do primeiro milênio. A época posterior à contrarreforma fortalece a forma monárquica de governo reforçando as prerrogativas papais. Igreja significa cada vez mais a própria instituição e a hierarquia, sendo uma sociedade perfeita apta a realizar sua finalidade. $\mathrm{O}$ advento da modernidade questionará seriamente a posição da Igreja na sociedade, privando-a de sua anterior influência em muitos setores, de seus privilégios, do monopólio da educação e da assistência social. A perda do poder "para fora" é compensada por um aumento do poder "para dentro", seja do papa, das congregações romanas, dos núncios apostólicos. Havia então um clima de hostilidade com relação à modernidade, vista como inimiga da Igreja. Esta concentrava sua ação em se defender da sociedade hostil, em se perpetuar em sua configuração 
tradicional, em enfatizar o doutrinal e o jurídico, em controlar o espaço de liberdade e de reflexão em seu interior.

João XXIII intuiu bem que esta situação era absurda e que levaria a Igreja a se tornar um gueto na sociedade moderna. Daí conclamar o Concílio Vaticano II que aceita dialogar com a sociedade civil, avaliar a cultura da modernidade assumindo alguns de seus elementos, atualizar sua pastoral levando a sério o contexto vital dos católicos, promover a inculturação da fé e as Igrejas Locais. O trabalho conjunto de uma plêiade de bispos e teólogos de grande competência recuperou as riquezas da teologia patrística, renovando a noção de revelação, da própria Igreja, da sua relação com o mundo, do culto litúrgico, do papel do laicato na missão eclesial, do diálogo com outros cristãos e com outras religiões. Embora muitas conquistas deste Concílio tenham chegado até nossos dias, sabemos que os anos turbulentos que se seguiram deram azo a uma reação posterior, que acentuou novamente a centralização romana, o controle da teologia, a hegemonia hierárquica, a uniformização da liturgia e o modesto papel do laicato. Não nos cabe julgar nossos antecessores e menos ainda suas intenções. Apenas constatar os fatos.

Vejamos de modo muito breve e incompleto a situação no Brasil. A união da Igreja e da Coroa na época colonial, no tempo do padroado, fez com que a Igreja se apoiasse no Estado e acabasse sendo vítima de uma fragilidade institucional, de uma pastoral de manutenção, de um pertencimento católico sem compromisso por parte do laicato. A crônica escassez de clero, as extensas regiões do país, a deficiente evangelização da população, irão ser remediadas em parte pela piedade medieval trazida de Portugal e responsável pela religiosidade popular do nosso povo. Portanto um catolicismo fortemente devocional como hoje constatamos. Com o advento da república a Igreja perde as regalias, mas ganha a liberdade. As mudanças ocorridas pela crescente modernização a partir de 1955 levarão a Igreja nos anos seguintes a se ocupar mais com as classes populares, a denunciar os abusos de autoridade do regime militar, a lutar pelos marginalizados na linha das Assembleias Episcopais do CELAM, a promover as Comunidades Eclesiais de Base, embora estas opções pastorais tenham experimentado certo esfriamento nos últimos anos. O aumento de evangélicos, sobretudo pentecostais, a histórica passividade do laicato, a falta de leigos/as bem formados, o escasso contingente de clero para um país continental, a controvertida estrutura paroquial nos grandes centros, as crescentes desigualdades sociais, as rápidas e sucessivas transformações da sociedade e uma deficiente formação do clero para enfrentá-las, eis alguns dos desafios que hoje encontramos. 
Por outro lado o nosso atual contexto sociocultural não é exatamente o mesmo da época do Vaticano II. A atual sociedade se encontra sujeita ao critério supremo da razão que decai facilmente no racionalismo. Além disso, devido à forte hegemonia do setor econômico, vivemos uma racionalidade de cunho funcional voltada para a produtividade e o lucro. Acrescentemos ainda que a atual cultura pluralista com abundante oferta de sentidos e de orientações descarrega sobre o indivíduo o ônus de escolher que direção dar a sua vida, que referencias e valores construirão sua autobiografia. E constatamos como os imperativos do bem-estar, da felicidade pessoal, do prazer imediato, do consumismo marcam a vida de muitos de nossos contemporâneos.

No momento em que os membros da Igreja estão vivendo nesta atual sociedade que os faz experimentar desafios existenciais, pluralidade de discursos, ausência de referências sólidas, condicionamentos culturais, individualismo reinante, excesso de informações, aceleração do tempo, superficialização da vida, é somente nesta situação concreta que poderão viver sua fé. Se continuamos a insistir numa linguagem inadequada e ininteligível, embora correta e ortodoxa, em elaborarmos discursos doutrinários e morais sem considerar devidamente as pessoas concretas, em dar mais valor à letra do que ao espírito, então a mensagem evangélica perde seu fascínio, sua força atrativa, sua potencialidade de despertar esperança e felicidade, de aliviar sofrimentos e encorajar iniciativas benéficas. Então as novas gerações poderão se sentir distanciadas desta instituição do passado, pesada, moralista, cujo discurso nem sempre é respaldado por seu testemunho de vida. O recurso a eventos de forte carga emotiva, em si positivo, pode enganar se não for seguido por um trabalho de evangelização em profundidade e de compromisso cristão no mundo.

\section{A Igreja desejada pelo papa Francisco}

Embora nos limitemos às linhas eclesiológicas presentes na Exortação Apostólica “A Alegria do Evangelho”, observemos que este texto pós-sinodal sobre a Nova Evangelização é apresentado pelo papa Francisco como um texto que "possui um significado programático e tem consequências importantes" (24). De fato já no início ele declara que a Exortação quer "indicar caminhos para o percurso da Igreja nos próximos anos" (1). Mesmo reconhecendo de antemão que não poderemos abordar todos os pontos de seu programa, vamos tratar de alguns deles que nos parecem mais pertinentes. 


\section{A. Uma Igreja missionária e descentrada}

Todo o sentido da vida de Jesus Cristo foi proclamar e realizar o Reino de Deus na humanidade. Sem este objetivo central sua pessoa se torna ininteligível. Este projeto salvífico de Deus, que já tivera início no Antigo Testamento, chega a sua plenitude na pessoa de Jesus Cristo, que em suas ações e palavras revela o gesto salvífico do Pai, seu amor e sua misericórdia incondicionada. Este Reino implica assumir o comportamento de Jesus que "passou por este mundo fazendo o bem" (At 10,38), mas conota também uma dimensão social, pois o indivíduo só pode ser feliz numa sociedade que reconheça e concretize o amor fraterno e a justiça. Esta tarefa de proclamar e realizar a Boa-Nova constitui o objetivo da evangelização e foi confiada por Jesus a seus discípulos e seguidores. Estes, portanto, constituem uma comunidade de fiéis, constituem a Igreja. Com outras palavras, todo o sentido da Igreja é estar a serviço da implantação do Reino de Deus; ela não é fim, ela é meio, instrumento de Deus, sinal e sacramento da salvação, pois deve visibilizar que este Reino não é uma utopia, mas uma realidade no interior da história da humanidade pelo testemunho de vida dos cristãos.

Daí a afirmação do papa Francisco: "a ação missionária é o paradigma de toda a obra da Igreja" (15). Com outras palavras, o salvifico é prioritário de tal modo que o doutrinal, o jurídico e o institucional estão a seu serviço e dele recebem seu sentido último. Esta era a convicção do próprio Jesus de Nazaré na crítica feita à religião de seu tempo. Esta era também a preocupação dos participantes do Concílio Vaticano II. Esta é ainda a razão de fundo para os pronunciamentos e decisões deste atual papa. Palavras como participação, descentralização, diálogo, espírito de serviço, sensibilidade humana, proximidade aos pobres e marginalizados, brotam de sua preocupação central com o Reino de Deus.

O papa Francisco considera a Igreja como "de saída", a qual em sua estrutura e em sua atividade se torne "um canal proporcionado mais à evangelização do mundo atual que à sua autopreservação" (27), sabendo "sair da própria comodidade e ter a coragem de alcançar todas as periferias que precisam da luz do Evangelho" (20). Os evangelizadores devem contrair "o cheiro das ovelhas" (24). Daí o apelo à renovação de toda a sua pastoral (11), que pressupõe "uma conversão pastoral e missionária" na linha do Documento de Aparecida (25). Como não é fácil romper com a inércia do status quo bem conhecido e familiar, o papa convida "todos a serem ousados e criativos" (33) nesta tarefa de repensar a ação pastoral da Igreja. 
Na fidelidade às diretrizes do Documento de Aparecida a Igreja do Brasil, nas últimas Diretrizes Gerais da Ação Evangelizadora, se considera "uma Igreja em estado permanente de missão" (DGAE 3.1), insistindo na formação de uma "consciência missionária" (DGAE 31), no anúncio do querigma (DGAE 32), na necessidade do testemunho pessoal (DGAE 33), na renovação das estruturas (DGAE 34) e na missão como fonte de todas as atividades (DGAE 35). Portanto, em perfeita sintonia com a Exortação Apostólica. Porém permanecem certas questões: estamos realmente convencidos desta verdade, nós todos, clero e laicato? Existem condições suficientes na Igreja para todos os católicos assumirem ativamente sua responsabilidade missionária? Não damos a impressão de nos preocuparmos com o enunciado doutrinal e com a norma canônica, em si necessários, mais do que com o anuncio da pessoa de Jesus Cristo? Não esconde o peso estático da instituição eclesial a verdade de uma comunidade viva e missionária? Não se encontra diminuído em parte do clero o zelo pastoral pelo impacto da atual sociedade (80)?

\section{B. Uma Igreja configurada colegialmente}

Já no Concílio Vaticano II era evidente a preocupação dos bispos em equilibrar a noção do primado conforme definida no Vaticano I e que ficara incompleta pela interrupção forçada deste Concílio. Basta que examinemos o número de intervenções sobre este tema. Mesmo sem entrarmos em detalhes e discussões posteriores podemos afirmar que a Constituição Dogmática Lumen Gentium fundamenta uma importante revalorização do corpo episcopal. Os bispos recebem o cargo de ensinar, santificar e governar do próprio Senhor Jesus Cristo, e não indiretamente do Papa, como se afirmava anteriormente, não podendo ser considerados "vigários do Sumo Pontífice" (LG 27), embora só possa ser exercido tal múnus em comunhão com a Cabeça e com os demais membros do colégio episcopal. Esse colégio com o Papa constitui a instância da autoridade suprema na Igreja, embora o Papa conserve seu poder primacial (LG 22). Consequentemente as Igrejas Locais podem ser por si mesmas sujeitos de pleno direito, bem como responsáveis pelas demais, sobretudo de sua região, o que na linha das antigas Igrejas patriarcais irá constituir as Conferências Episcopais (LG 23).

O papel da sede romana como sinal da unidade da Igreja é de fortalecer a comunhão entre as Igrejas Locais, não assumindo suas funções e competências. No primeiro milênio da Igreja era viva e atuante essa "eclesiologia 
de comunhão", sendo que a estrutura patriarcal mantinha a diversidade e a unidade da Igreja. O patriarca num regime sinodal, isto é, com os demais bispos, resolvia as questões de cunho litúrgico ou de direito canônico. A uniformidade do direito eclesiástico, da liturgia e o controle das sedes episcopais por Roma não provêm necessariamente do primado como tal.

Embora a doutrina conciliar tenha produzido mudanças que revalorizaram o episcopado no seio da Igreja (Sínodo dos bispos, Conferências Episcopais nacionais e regionais) não podemos negar um retrocesso para uma centralização indevida. Tal já aparece no Novo Código de Direito Canônico (1983) que teve que completar o que os padres conciliares não fizeram, a saber, a forma jurídica das reformas desejadas, fazendo-o entretanto de modo unilateral prescrevendo estreita dependência dos bispos com relação ao Papa. O motu proprio Apostolos suos (1998) retira das Conferências Episcopais seu magistério doutrinal, exigindo unanimidade nas decisões, e privando-as de desempenhar um papel análogo ao dos patriarcados. A fragilidade de certas Igrejas Locais, sua incapacidade para enfrentar problemas doutrinais, o impacto de uma sociedade pluralista, podem explicar em parte esta preocupação do governo da Igreja, mas suas funestas consequências são experimentadas por todos nós: nomeação de bispos que fortalecessem esta centralização romana, incentivo ao carreirismo eclesiástico, volta a uma Igreja de poder e prestígio, esfriamento de sua dimensão profética, queda em seu compromisso com os mais pobres, ênfase em seu aspecto institucional e jurídico, emergência de um clero mais voltado para o culto e o poder.

O papa Francisco pleiteia na linha de Aparecida uma reforma das estruturas, as quais devem ser "mais missionárias" (27), pois "há estruturas eclesiais que podem chegar a condicionar um dinamismo evangelizador" (26). E afirma incisivamente: "Uma centralização excessiva, em vez de ajudar, complica a vida da Igreja e sua dinâmica missionária" (32). Com relação às Conferências Episcopais seu pensamento é claro: "O Concílio Vaticano II afirmou que, à semelhança das antigas Igrejas Patriarcais, as Conferências Episcopais podem 'aportar uma contribuição múltipla e fecunda, para que o sentimento colegial leve a aplicações concretas' (LG 23). Mas este desejo não se realizou plenamente, porque ainda não foi suficientemente explicitado um estatuto das Conferências Episcopais que as considere como sujeitos de atribuições concretas, incluindo alguma autêntica autoridade doutrinal" (32). E acrescenta noutra parte: "Não convém que o Papa substitua os episcopados locais no discernimento de todas as problemáticas que sobressaem nos seus territórios" (16). 
Creio que o papa espera uma maior colaboração das Conferências Episcopais para o desempenho de seu múnus petrino. Alguns exemplos: a nossa Igreja apresenta uma ausência de celebração da eucaristia em muitas comunidades. Mesmo reconhecendo nelas a presença atuante da Palavra de Deus, como deveria o episcopado brasileiro tratar desta lacuna? Ou considerar uma possível revisão da linguagem litúrgica que pudesse realmente ser entendida pelo nosso povo? Ou ainda pleitear uma maior participação das Igrejas Locais na nomeação de novos bispos?

\section{Uma Igreja inculturada}

Intimamente relacionada com a Igreja Local está a questão da inculturação da fé. Vejamos. A iniciativa salvífica de Deus só chega a sua meta quando é livremente acolhida pelo ser humano na fé. Só temos propriamente revelação ou Palavra de Deus no interior de uma resposta de fé, ela mesma fruto da ação de Deus em nós. Portanto, o acolhimento na fé é parte constitutiva da revelação; sem ela os eventos salvíficos seriam meros fatos históricos, a Palavra de Deus seria palavra humana e a pessoa de Jesus Cristo nos seria desconhecida, como o foi para os fariseus de seu tempo. Porém o ser humano que professa sua fé vive necessariamente num contexto sociocultural que lhe fornece linguagem, valores, padrões de comportamento, vida social e capacidade de se desenvolver como ser humano. Portanto, ao captar e acolher a Palavra de Deus o ser humano o estará fazendo necessariamente dentro de sua cultura própria. Assim só podemos encontrar a Palavra de Deus ou o Evangelho já inculturados.

Sendo a fé o fundamento da comunidade eclesial, como nos ensina Santo Tomás de Aquino, encontra-se a Igreja enquanto comunidade de fiéis inevitavelmente no interior de uma cultura que determinará como seus membros entendem e vivem a fé cristã. Deste modo a Igreja Local implica sempre uma Igreja inculturada. Portanto, se ela quer ser entendida como sinal da salvação ela deve assumir a linguagem, as categorias mentais, os gestos, os costumes, o saber e as artes da cultura onde se encontra inserida, como tanto insistia João Paulo II. Entretanto a cultura não é uma realidade estática, mas propriamente um processo, devido aos novos desafios de dentro e de fora que a atingem. Portanto deve a comunidade eclesial saber acolher em si as transformações necessárias para poder levar a cabo sua missão. O Concílio Vaticano II expõe este ensinamento no Decreto $\mathrm{Ad}$ Gentes sobre a atividade missionária da Igreja (AG 15;22). 
Francisco acolhe sem mais a antropologia cultural subjacente ao texto conciliar e termina taxativamente: "A graça supõe a cultura, e o dom de Deus encarna-se na cultura de quem o recebe" (115). Deste modo "o cristianismo não dispõe de um único modelo cultural, mas permanecendo o que é, (...) assumirá também o rosto das diversas culturas e dos vários povos onde for acolhido e se radicar" (116). E fazendo suas as afirmações anteriores de João Paulo II sobre esta temática assevera que "cada cultura oferece formas e valores positivos que podem enriquecer o modo como o Evangelho é pregado, compreendido e vivido" e assim manifesta a Igreja sua catolicidade (116). Reconhece o papa que o processo de inculturação é lento e exige das Igrejas Locais criatividade e ousadia (129). Pensemos em nosso país com uma rica diversidade cultural (DGAE 73), mas que, apesar de algumas iniciativas locais, emprega as mesmas expressões, os mesmos ritos, as mesmas linhas pastorais. Não seria o momento de reivindicar certa liberdade para os regionais da CNBB assumirem mais as culturas locais? Não confundimos, às vezes, unidade com uniformidade (117)? Somos fiéis a uma formulação, mas transmitimos realmente a substância da verdade salvífica (41)? Buscamos novos sinais, novos símbolos, nova carne, para a transmissão da Palavra de Deus (167)?

D. Uma Igreja de discípulos missionários

Todos os membros da Igreja constituem o Povo de Deus, todos estão portanto incumbidos de proclamar a Boa-Nova de Jesus Cristo para a sociedade. Devemos corrigir uma imagem de uma Igreja clerical ativa diante de um laicato passivo. Todos na Igreja gozam de igual "dignidade e ação comum" (LG 32), todos participam ativamente da ação evangelizadora da Igreja no mundo, sentido último da própria comunidade eclesial que eles próprios constituem. Portanto, todos na Igreja (LG 30), pelo fato de serem batizados (LG 33), independentemente de sua condição no interior dela, devem anunciar a salvação de Cristo e promover os valores evangélicos na sociedade, sendo assim sujeitos ativos na Igreja. Portanto, todo católico é sujeito eclesial por ser batizado e não por alguma delegação posterior da autoridade. Daí brota "o direito e o dever" de exercer seus carismas para o bem dos homens e a edificação da Igreja (AA 3). A ação pastoral no interior da Igreja vai ser incrementada nos anos posteriores ao Concílio pela renovação dos ministérios, abrindo assim novos campos de atuação (catequese, promoção humana, obras de caridade, coordenação pastoral, assessoria das mais diversas, animação litúrgica, ensino teológico). 
Observemos que o Documento de Aparecida, no qual o atual papa teve influência direta como presidente da Comissão de Redação, acolhe o ensinamento conciliar, reconhece os leigos e leigas como "verdadeiros sujeitos eclesiais", interlocutores competentes entre a Igreja e a sociedade (DAp 497a), recomendando que os bispos devam "abrir para eles espaços de participação e confiar-lhes ministérios e responsabilidades" (DAp 211). Dotados de uma formação adequada (DAp 212), devem os fiéis leigos/as "ser parte ativa e criativa na elaboração e execução de projetos pastorais a favor da comunidade" (DAp 213), participando "do discernimento, da tomada de decisões, do planejamento e da execução" (DAp 371). Naturalmente o mesmo documento adverte para a necessidade de uma mudança de mentalidade de todos na Igreja, especialmente da hierarquia (DAp 213).

Francisco em sua Exortação Apostólica deixa bem claro que irá insistir nesta conquista do Concílio Vaticano II enfatizada na Assembleia Episcopal em Aparecida: "Cada um dos batizados, independentemente da própria função na Igreja e do grau de instrução da sua fé, é um sujeito ativo de evangelização" (120). A missão não é apenas um ornamento ou um apêndice na pessoa do cristão; é algo que não se pode arrancar de si sem se destruir (273). Mesmo mencionando a necessidade de uma melhor formação (121), o papa insiste na evangelização pelo contato pessoal (127), já que se trata de comunicar aos outros a própria experiência salvífica do encontro com Jesus Cristo, à semelhança dos primeiros discípulos, da samaritana e de Paulo (120). Mas também reconhece a dificuldade dos leigos/as por não encontrarem espaço nas Igrejas Locais, em parte devido a um excessivo clericalismo (102). Sem dúvida alguma a Igreja no Brasil carece de um laicato bem formado, não só com atuação restrita às tarefas pastorais tradicionais, mas realmente empenhado em testemunhar sua fé nos areópagos modernos, sobretudo nos campos do saber e nos locais onde atuam. O que falta? Incentivo da hierarquia? Liberdade de expressão? Deficiência intelectual nos responsáveis? Força do clericalismo? Trabalhamos realmente para convencer os leigos/as, mesmo os mais simples, de que são capazes para a missão? Priorizamos uma sólida formação do clero, humana e espiritual, filosófica e teológica, mesmo tendo que rever as estruturas desta formação (Discurso do papa ao episcopado brasileiro n.4)? Como tornar tal formação não apenas algo a ser sabido, mas principalmente a ser vivido? 


\section{E. Uma Igreja que testemunhe na vida a sua fé em Jesus Cristo}

Sem desconhecer os exemplos de tantos cristãos que viveram sua fé de modo autêntico e generoso, não podemos deixar de caracterizar a Igreja que herdamos como uma realidade na qual o doutrinal dominava o existencial, o jurídico se impunha ao sacramental, o institucional prevalecia sobre o místico, certo tradicionalismo impedia renovações urgentes, o medo da novidade impedia o eclodir de novos caminhos evangelizadores, a mentalidade do poder eclesiástico emudecia a verdade do serviço eclesiástico. Toda renovação eclesial implica um retorno ao mais nuclear da fé cristã, à vivência cristã das primeiras comunidades, talvez encobertas pelas doutrinas, normas, regulamentações, tradições que se lhes agregaram ao longo da história, certamente para explicitar e salvaguardar este núcleo evangélico, mas que não deixaram de obscurece-lo por ocuparem um lugar central que não é o seu. Este fato não passou desapercebido ao papa Francisco, como iremos ver.

Primeiramente ele enfatiza a importância decisiva do Espírito Santo na vida da Igreja. De fato, se a Igreja é a comunidade dos que creem em Jesus Cristo, então toda ela está fundamentada na ação do Espírito Santo. Pois só podemos confessar Jesus Cristo como Senhor pela ação do Espírito Santo (1Cor 12,3). É a participação de todos no mesmo Espírito que gera a comunhão (2Cor 13,13: genitivo objetivo). O Espírito que esteve presente e atuante na existência de Jesus continua atuando hoje nos cristãos (LG 7). Francisco distingue uma evangelização vista como "um conjunto de tarefas vividas como obrigação pesada" da "evangelização com espírito", isto é, "com o Espírito Santo, já que Ele é a alma da Igreja evangelizadora" (261). E completa: "Para manter vivo o ardor missionário, é necessária uma decidida confiança no Espírito Santo", pois "não há maior liberdade do que a de se deixar conduzir pelo Espírito", "permitindo que Ele nos ilumine, guie, dirija e impulsione para onde Ele quiser" (280).

Numa época marcada pela inflação de palavras através dos vários meios de comunicação social e também de certo ceticismo com relação às ideologias e cosmovisões, ganha a experiência pessoal um peso enorme para fundamentar as convicções pessoais. Esta realidade atinge também a fé dos cristãos. Esta resulta de uma iniciativa de Deus de vir ao nosso encontro, doando-Se a si próprio em Jesus Cristo e no Espírito Santo, iniciativa que se realiza plenamente ao ser acolhida pelo cristão na fé. Portanto a fé é um evento salvifico na vida da pessoa que é, de certo modo, por ela experimentado. Esta experiência 
atinge o coração de cada um, não só dando sentido à existência humana, mas também consolando, fortalecendo e iluminando os que a fazem. É a experiência do amor, da bondade e da misericórdia de Deus, realidade prioritária e fundamental em nossa vida. O papa bate na mesma tecla ao enfatizar a importância da experiência pessoal com Jesus Cristo, do amor de Deus que Ele nos revela. Em suas palavras: "O verdadeiro missionário (...) sabe que Jesus caminha com ele, fala com ele, respira com ele, trabalha com ele" (266).

Ao iniciar sua vida pública Jesus proclama: "Completou-se o tempo, e o Reino de Deus está próximo. Convertei-vos e crede na Boa-Nova" (Mc 1,15). É uma conversão intimamente relacionada com o Reino de Deus, pois significa acolher na fé a salvação definitiva de Deus na pessoa de Jesus Cristo como núcleo da própria existência. Esta conversão deve estar presente na vida do cristão como uma atitude de fundo que o acompanha sempre. E também na vida da Igreja, seja em sua consciência, seja em suas instituições. Esta exigência aparece claramente no Documento de Aparecida, tanto em seu aspecto pessoal (DAp 366), que inclui uma mudança de mentalidade eclesial por parte de todos, especialmente do clero (DAp 213), quanto em sua dimensão institucional (DAp 365), acionada pelo que o texto chama de conversão pastoral. Francisco demonstra clara consciência do desafio da renovação eclesial e conclama todos a uma "conversão pastoral e missionária" na linha de Aparecida (25). Entretanto o papa inova ao apontar bem concretamente o que necessita de conversão: mundanismo espiritual dos que buscam a si próprios, a glória humana e o bem-estar pessoal sob as aparências de religiosidade (93), uma fé prisioneira de um racionalismo subjetivo ou de "uma suposta segurança doutrinal ou disciplinar que dá lugar a um elitismo narcisista e autoritário, onde, em vez de evangelizar, se analisam e classificam os demais" (94). Menciona ainda o exibicionismo na liturgia, na doutrina e no prestígio da Igreja, o fascínio das conquistas pessoais e autorreferenciais, bem como das estatísticas e das avaliações. E termina: "Quem caiu nesse mundanismo olha de cima e de longe, rejeita a profecia dos irmãos, desqualifica quem o questiona, faz ressaltar constantemente os erros alheios e vive obcecado pela aparência" (97). E conclui: "Deus nos livre de uma Igreja mundana sob vestes espirituais e pastorais!" (97). Os objetivos de conversão elencados pelo papa são bastante claros. Incumbe-nos saber como realizá-los. Como valorizar o papel do Espírito Santo na vida e na missão dos fiéis? Como levar adiante uma pastoral mistagógica? Como proporcionar um encontro pessoal de cada um com Jesus Cristo? Como fazê-lo ultrapassar uma religião 
de práticas e normas? Como ser uma Igreja da "misericórdia gratuita" (114)? Como combater o individualismo que atinge a todos nós na Igreja (DGAE 22) e viver a gratuidade do amor cristão?

\section{F. Uma Igreja dos pobres}

Conhecemos a tentativa de um grupo de bispos, por ocasião do Concílio Vaticano II, em promover uma maior simplicidade e austeridade na Igreja. Estavam bem conscientes de que muitos símbolos de poder e riquezas foram se agregando ao longo dos séculos à instituição eclesial. Contudo tais esforços apenas resultaram numa pequena menção, meio perdida no interior de um texto conciliar: “... assim como Cristo realizou a obra da redenção na pobreza e na perseguição, assim a Igreja é chamada a seguir pelo mesmo caminho para comunicar aos homens os frutos da redenção" (LG 8). Entretanto sabemos também que os bispos latino-americanos, na linha traçada pela Gaudium et Spes voltaram-se para a sofrida existência da grande população deste subcontinente e através das Assembleias Gerais do CELAM (Medellin, Puebla, Santo Domingo, Aparecida) enfatizaram a opção pelos pobres, a luta por uma sociedade mais justa, a denúncia de ideologias desumanizantes. Certos exageros de cunho ideológico e certa resistência em abandonar vantagens adquiridas propiciaram uma reação por parte do Vaticano. Bispos e padres mais identificados com a causa dos pobres viram-se olhados com suspeita, criticados e mesmo marginalizados, arrefecendo assim todo um ardor de cunho eminentemente evangélico.

Felizmente em Aparecida os bispos participantes reagiram, não se contentando com uma Igreja voltada para os pobres, mas exigindo que o imperativo da pobreza evangélica atingisse também as pastorais e as instituições da Igreja. E a razão dada era sempre a mesma: "A Igreja deve cumprir sua missão seguindo os passos de Jesus e adotando suas atitudes" (DAp 31). O texto reconhece que nos afastamos do Evangelho e que devemos adotar "um estilo de vida mais simples, austero e solidário, mais fiel à verdade e à caridade" (DAp 100h). Para que essas belas palavras não permaneçam inócuas, sem verdadeira incidência em nossos comportamentos e decisões, é necessário que se manifestem em opções e gestos concretos, tais como saber escutar os pobres, dedicar-lhes tempo, acompanha-los nas horas mais difíceis (DAp 397). Não se nega que isto já esteja acontecendo, mas aqui se trata de urgir toda a Igreja, seu modo de vida, sua atividade pastoral e suas estruturas, mesmo reconhecendo que o problema da pobreza no mundo é bastante mais complexo. Quando será 
a Igreja verdadeiramente a "casa dos pobres de Deus" como afirma o texto de Aparecida (DAp 524)?

Ao tratar da dimensão social da evangelização no capítulo IV da Exortação Apostólica o papa Francisco inicia com uma afirmação que diz tudo: "Evangelizar é tornar o Reino de Deus presente no mundo" (176). Pois o mesmo não é apenas uma realidade espiritual, mas atinge o ser humano em todas as suas dimensões, de tal modo que afirma mais adiante: "Deus, em Cristo, não redime somente a pessoa individual, mas também as relações sociais entre os homens" (178); daí que "na medida em que Ele conseguir reinar entre nós, a vida social será um espaço de fraternidade, de justiça, de paz, de dignidade para todos" (180). De fato, no Novo Testamento se exprime a absoluta prioridade da 'saída de si próprio para o irmão' como um dos fundamentos de toda norma moral e critério de crescimento espiritual (179). Daí o papa poder afirmar: "Uma fé autêntica, que nunca é cômoda ou individualista, comporta sempre um profundo desejo de mudar o mundo, transmitir valores, deixar a terra um pouco melhor depois da nossa passagem por ela" (183).

O papa lembra que "cada cristão e cada comunidade são chamados a ser instrumentos de Deus a serviço da libertação e promoção dos pobres" (187) e insiste na palavra "solidariedade" enquanto expressa "uma nova mentalidade que pense em termos de comunidade, de prioridade da vida de todos sobre a apropriação dos bens por parte de alguns" (188), sobretudo hoje quando experimentamos na sociedade "um novo paganismo individualista" (195). Assim não nos admira que Francisco tenha recebido fortes críticas de certos setores da sociedade. Ele retoma com força a opção pelos pobres ao afirmar sem rodeios: "desejo uma Igreja pobre para os pobres" e reafirma a experiência da Igreja latino-americana de que os pobres nos evangelizam (198). Para ele o anuncio do Reino hoje só se torna significativo e digno de fé se for acompanhado de uma proximidade real com os pobres (199). Termina lamentando o que estes últimos sofrem por falta de cuidado espiritual (200). Daí nos perguntarmos: num mundo onde a maioria da população carece dos bens necessários a uma vida digna, como levar a Igreja a uma vida simples e sóbria? Como evitar que caia no "mundanismo espiritual" (207) por não se ocupar com os mais pobres? Como formar o clero para resistir à tentação de ascensão social, poder e consumo de bens, incutida pela atual sociedade? Como ir ao encontro dos marginalizados, dos inúteis, dos excluídos da atual sociedade?

Como disse ao início desta exposição, ela não exaure toda a riqueza temática da Exortação papal, mas procurou deixar clara a intenção do atual 
pontífice de empreender uma renovação eclesial. E certamente a colaboração de cada um de nós será certamente decisiva para a missão da Igreja em prol do Reino de Deus.

\section{SIGLAS:}

DGAE: Diretrizes Gerais da Ação Evangelizadora da Igreja no Brasil (2011-2015). Os números entre parêntesis se referem à Exortação Apostólica Evangelii Gaudium.

Mario de França Miranda Doutor em Teologia Sistemática pela PUG - Roma Professor de Teologia na PUC-Rio Rio de Janeiro/RJ - Brasil E-mail: mfranca@puc-rio.br

Recebido em: 12/05/14 Aprovado em: 12/05/14 